\title{
Columnar Thermal Barrier Coatings Produced by Different Thermal Spray Processes
}

\author{
Nitish Kumar ${ }^{1} \cdot$ Mohit Gupta $^{1}\left([) \cdot\right.$ Daniel E. Mack $^{2} \cdot$ Georg Mauer $^{2} \cdot$ \\ Robert Vaßen ${ }^{2}$
}

Submitted: 19 February 2021 / in revised form: 8 June 2021 / Accepted: 9 June 2021 / Published online: 6 July 2021

(C) The Author(s) 2021

\begin{abstract}
Suspension plasma spraying (SPS) and plasma spray-physical vapor deposition (PS-PVD) are the only thermal spray technologies shown to be capable of producing TBCs with columnar microstructures similar to the electron beam-physical vapor deposition (EB-PVD) process but at higher deposition rates and relatively lower costs. The objective of this study was to achieve fundamental understanding of the effect of different columnar microstructures produced by these two thermal spray processes on their insulation and lifetime performance and propose an optimized columnar microstructure. Characterization of TBCs in terms of microstructure, thermal conductivity, thermal cyclic fatigue lifetime and burner rig lifetime was performed. The results were compared with TBCs produced by the standard thermal spray technique, atmospheric plasma spraying (APS). Bondcoats deposited by the emerging high-velocity air fuel (HVAF) spraying were compared to the standard vacuum plasma-sprayed (VPS) bondcoats to investigate the influence of the bondcoat deposition process as well as topcoat-bondcoat interface topography. The results showed that the dense PS-PVD-processed TBC had the highest lifetime, although at an expense of the highest thermal conductivity. The reason for this behavior was attributed to the dense intracolumnar structure, wide intercolumnar gaps and high column density, thus improving the strain tolerance and fracture toughness.
\end{abstract}

Mohit Gupta

mohit.gupta@hv.se

1 University West, 46186 Trollhättan, Sweden

2 Forschungszentrum Jülich GmbH, D-52425 Jülich, Germany
Keywords burner rig testing · columnar microstructure lifetime - thermal barrier coatings - thermal conductivity . thermal cyclic fatigue

\section{Introduction}

Thermal barrier coatings (TBCs) play a crucial role in modern gas turbine engines used in aero-engines, power generation and marine applications to protect the underlying metal substrate from high working temperatures by facilitating a temperature gradient. Recent developments in the turbines for power generation and aviation sector had led to a point where operating conditions have exceeded the upper limits of most of the conventional TBCs (Ref 1). In order to meet the increasing demands in the gas turbine technology, one focus of researchers is the developing of new TBC architectures. TBCs are typically a bilayer material system consisting of a ceramic topcoat (TC) layer and a metallic bondcoat (BC) layer. The main purpose of metallic $\mathrm{BC}$ is to improve the adhesion between the underlying substrate and $\mathrm{TC}$ and to provide resistance to oxidation (Ref 2-4). Ceramic TC is the main insulating layer of the system. 6-8\% Yttria-stabilized zirconia (YSZ) is the state-of-the-art TC material used in TBCs. Due to the porosity and also the good ionic conductivity, oxygen can easily diffuse through the ceramic TC; as a result, a slow growing aluminum oxide film known as the thermally grown oxide (TGO) layer is formed at high operation temperatures from an aluminum-enriched composition of BC (Ref 5, 6). There are several ways to deposit TBCs. The two most widely used methods to deposit ceramic TCs are atmospheric plasma spray (APS) and electron beam-physical vapor deposition (EB-PVD). TCs deposited by APS typically have a lamellar microstructure with the presence 
of micro-cracks and globular pores; on the other hand, the TCs in EB-PVD-processed TBCs have a strain-tolerant columnar microstructure. EB-PVD-processed columnar microstructure TBCs exhibit high in-plane strain tolerance because of which they are of high interest. APS-deposited coatings show lower thermal conductivity than EB-PVD coatings due to the presence of globular pores and interlamellar (micro-)cracks present in the coatings (Ref 7). As compared to APS, EB-PVD TBCs have been reported to show a higher thermal cyclic lifetime due to the presence of a strain-tolerant columnar microstructure (Ref 8). However, APS process shows more operational robustness and economic viability than EB-PVD (Ref 9).

Suspension plasma spray (SPS) is an emerging process that comes with a possibility to deposit coatings with the strain-tolerant columnar microstructure similar to EBPVD, but with lower thermal conductivity (Ref 10). Plasma spray-physical vapor deposition (PS-PVD) is another evolving technique that evaporates the feedstock to form a coating with a columnar microstructure from the gas phase similar to EB-PVD. SPS and partially also PS-PVD are of commercial interest since these techniques are considerably cheaper than EB-PVD in terms of both running cost and equipment cost (Ref 11-13). SPS is a modification of the APS process where the feedstock is in the form of suspension instead of powder. The suspension is made of fine-sized particles of ceramics suspended in a solvent (typically water or ethanol). In conventional APS, it is not possible to deposit powder particle with nanometric or submicrometric size due to limitations such as agglomeration of powder particles during storing and feeding into the equipment, and also fine powder particles would not impart enough momentum to penetrate the high-velocity plasma stream (Ref 14, 15). Bernard et al. demonstrated that the SPS TBCs showed lower thermal conductivity compared to EB-PVD as well as APS TBCs (Ref 11). Kaßner et al. reported that SPS TBCs could exhibit a wide range of porosity levels (up to 40\%) unlike APS, which greatly reduces the thermal conductivity of SPS TBCs as compared to APS TBCs (Ref 16). Also, Lima et al. tested and compared erosion performance of SPS, EB-PVD and APS coatings and concluded that under the used conditions SPS outperformed EB-PVD and APS coatings (Ref 17).

PS-PVD is a hybrid technique that was developed by Oerlikon Metco AG (Switzerland). This technology is based on low-pressure plasma spraying (LPPS), also known as vacuum plasma spraying (VPS), which is carried out at a pressure of 5-20 kPa (Ref 13). In the LPPS system, when the pressure is further reduced to $50-200 \mathrm{~Pa}$, the process is then known as very low-pressure plasma spraying (VLPPS) that is used to deposit uniform and thin coatings with a large area of coverage. PS-PVD system was developed by the addition of enhanced electric power input up to $180 \mathrm{~kW}$ to VLPPS, together with the low chamber pressure enabling the plasma jet to be lengthened to more than $2 \mathrm{~m}$ and its diameter in the range of $200-400 \mathrm{~mm}$ (Ref 18, 19). Using this PS-PVD setup, it is possible to evaporate the powder feedstock material with specific process parameters so that nano-sized condensates are deposited (Ref 18). Since the plasma stream enables the feedstock to be vaporized, it permits a non-line of sight deposition as compared to conventional thermal spray techniques which can be favorable to coat complex-shaped components (Ref 13). Vapor deposition of feedstock powder enables the formation of a coating with a strain-tolerant columnar microstructure. In order to obtain the desired columnar microstructures, it is necessary to provide moderate powder feeding rates, special selection of gases, powder with low granularity, a large spraying distance and specific gun traverses with the required gas flow characteristics (Ref 19). Góral et al. demonstrated that the coatings obtained by PS-PVD have better erosion resistance than conventional APS coatings but lower than EB-PVD-processed TBCs (Ref 19). Similar results were obtained by von Niessen et al. (Ref 20). Also, thermal cyclic fatigue tests were performed by von Niessen et al. where it was found that TBCs obtained by PS-PVD showed better lifetime than EB-PVD-processed TBCs (Ref 20). The burner rig lifetime of PS-PVD TBCs was found to be two times higher than the conventionally sprayed APS TBCs (Ref 13).

Certainly, the specific results depend on the specific columnar microstructure of both the SPS and PS-PVD coatings. In general, SPS and PS-PVD offer high potential for exhibiting better performance than state-of-the-art TBC manufacturing processes like APS and partly EB-PVD. SPS and PS-PVD processes are the only thermal spray techniques that can yield a strain-tolerant columnar microstructure similar to EB-PVD process. This has motivated to identify and distinguish the properties of SPS and PS-PVD TBCs such as microstructure, thermal conductivity, thermal cyclic fatigue (TCF) lifetime and burner rig. The objective of this study was to perform a structured comparative analysis of SPS and PS-PVD TBCs with APS TBCs as reference and achieve fundamental understanding of the effect of different columnar microstructures on their performance. In the end, design of an optimized columnar microstructure has been proposed. The BCs in this study were produced by the emerging high-velocity air fuel (HVAF) spraying and the standard VPS for comparison. It has been highlighted in the previous studies that $\mathrm{BC}$ surface topography and deposition techniques can have a significant influence on TBC lifetime (Ref 13, 21-23). The effect of BC deposition process (HVAF and VPS) and interface topography on TGO growth and failure mechanisms has been discussed in each case. 


\section{Experimental Methods}

\section{Sample Preparation}

In this study, Inconel 738LC was used as the substrate material. Button-shaped substrates with dimensions $25.4 \mathrm{~mm}$ diameter and $3 \mathrm{~mm}$ thickness were utilized for the microstructure analysis and TCF testing. For thermal conductivity measurements, plate-shaped substrates with dimensions $50 \mathrm{~mm} \times 30 \mathrm{~mm} \times 1.54 \mathrm{~mm}$ were used. For burner rig lifetime testing, specific button-shaped substrates with dimensions $30 \mathrm{~mm}$ diameter and $3 \mathrm{~mm}$ thickness were used. Nine different microstructures were deposited in this study as listed in Table 1. A TC and BC thickness of about $300 \mu \mathrm{m}$ and $200 \mu \mathrm{m}$, respectively, was targeted. The BCs were deposited by HVAF and VPS process using NiCoCrAlYHfSi (AMDRY 386 Oerlikon Metco, Switzerland) feedstock powder at University West, Sweden, and Forschungszentrum Jülich, Germany, respectively. The HVAF BCs were sprayed using M3 supersonic HVAF spray gun (UniqueCoat, Richmond, USA). The VPS BCs and APS TCs were sprayed using a multicoat system (Oerlikon Metco, Wohlen, Switzerland) and a F4-VB plasma torch at Forschungszentrum Jülich. The SPS TCs were sprayed using Mettech Axial III gun with Nanofeed 350 suspension feeder (Northwest Mettech Corp., Vancouver, Canada) at University West. The feedstock material for SPS TC was YSZ suspension in ethanol with a $25 \%$ solid load and $\mathrm{d}_{50}=500 \mathrm{~nm}$ (Treibacher Industrie AG, Austria). The APS YSZ powder was a 7YSZ Amperit powder (HC Starck Amperit 827.006, $d_{10}=54$ $\mu \mathrm{m}, d_{50}=80 \mu \mathrm{m}$ and $d_{90}=112 \mu \mathrm{m}$ ), and for PS-PVD, the feedstock powder was a 7YSZ produced by Oerlikon Metco designated as M6700. The spray system for PS-PVD TCs was the same multicoat system as used for VPS at Forschungszentrum Jülich, however, using the more powerful 03CP torch (Oerlikon Metco). Before depositing the $\mathrm{TC}$, all BCs went under vacuum heat treatment at $1120{ }^{\circ} \mathrm{C}$

Table 1 Samples analyzed in this study

\begin{tabular}{llll}
\hline Sl. no. & \multicolumn{1}{c}{ BC } & \multicolumn{1}{c}{ TC } & Abbreviation \\
\hline 1. & VPS & APS standard & V-A(s) \\
2. & VPS & APS porous & V-A(p) \\
3. & VPS & SPS porous & V-S $(\mathrm{p})$ \\
4. & HVAF & APS standard & $\mathrm{H}-\mathrm{A}(\mathrm{s})$ \\
5. & HVAF & SPS porous & $\mathrm{H}-\mathrm{S}(\mathrm{p})$ \\
6. & HVAF & SPS dense & $\mathrm{H}-\mathrm{S}(\mathrm{d})$ \\
7. & HVAF polished & SPS porous & $\mathrm{H}(\mathrm{pl})-\mathrm{S}(\mathrm{p})$ \\
8. & HVAF polished & PS-PVD porous & $\mathrm{H}(\mathrm{pl})-\mathrm{P}(\mathrm{p})$ \\
9. & HVAF polished & PS-PVD dense & $\mathrm{H}(\mathrm{pl})-\mathrm{P}(\mathrm{d})$ \\
\hline
\end{tabular}

and $845^{\circ}$ for $2 \mathrm{~h}$ and $24 \mathrm{~h}$, respectively, in sequence. Polishing of the bondcoat surface was performed on a semiautomatic single wheel grinder Saphir 550 (ATM Qness $\mathrm{GmbH}$, Mammelzen, Germany) using SiC grinding paper (mesh 1200) and a pressing force of $20 \mathrm{~N}$ at a wheel speed of $150 \mathrm{rpm}$. The final arithmetic mean surface roughness achieved was $R_{a}=0.05-0.1 \mu \mathrm{m}$.

The sample abbreviations in this study are based on BC (BC property)-TC (TC property) format. In Table 1, sample 1, i.e., V-A(s), is the standard reference sample produced by thermal spraying for comparison with the other TBCs. V-S(p) can be compared with V-A(s) to study behavior of APS and SPS porous TCs with VPS BC in various tests being carried out in the study. The behavior of VPS and HVAF BC during high-temperature exposure can be studied by comparing $\mathrm{V}-\mathrm{A}(\mathrm{s})$ to $\mathrm{H}-\mathrm{A}(\mathrm{s})$ and $\mathrm{V}-\mathrm{S}(\mathrm{p})$ to $\mathrm{H}-\mathrm{S}(\mathrm{p})$ where the TCs are similar but the only difference is the BC spray process. A comparison of SPS porous and SPS dense TC can be made from H-S(p) and H-S(d) where both the samples have the same HVAF-sprayed BC. Similarly, PS-PVD TC with a porous and dense microstructure can be studied in terms of microstructure and results obtained from the high-temperature exposure.

\section{Microstructure Characterization}

For the microstructural characterization of the TBCs, assprayed as well as failed samples were first cold mounted with low-viscosity epoxy resin, sectioned along the cross section and then mounted again with high-viscosity epoxy resin followed by grinding and polishing. The grinding and polishing were carried using semiautomatic Buehler AutoMet 300 Pro (Buehler, IL, USA) grinder-polisher system. The microstructure of polished samples was analyzed by scanning electron microscopy (SEM) using a HITACHI TM3000 (Japan) microscope. For the characterization of the burner rig samples, a SEM from Zeiss (Ultra 55 FEG-SEM, Carl Zeiss Microscopy GmbH, Germany) was used. The top-view SEM micrographs of assprayed and failed samples were also taken using the SEM. The BC and TC thickness was measured from the crosssectional SEM micrographs captured at 200x magnification. Ten values were measured at different positions throughout the coating, each for $\mathrm{BC}$ and $\mathrm{TC}$ thickness calculations.

\section{Porosity Analysis}

The porosity in as-sprayed TBCs was measured by an image analysis technique using free public domain software, Image J (Ref 24), at two different scales due to the inherent wide range of pore size distribution in SPS TBCs (Ref 25). SEM micrographs were captured at $500 \times$ and 
$5000 \times$ magnification for all of the TBCs. In the case of columnar TBCs, low-magnification $(500 \times)$ micrographs capture the microstructural features (intercolumnar gaps, micrometric pores, large cracks) that contribute to the coarse porosity, whereas the higher-magnification $(5000 \times)$ micrographs capture the fine-scale porosity inside the columns. Ten SEM micrographs of the cross section were taken at $500 \times$ and $5000 \times$ magnifications for all the TBCs. These micrographs were then extracted into the software and converted from grayscale to binary images. The $500 \times$ micrographs were then processed to contain only porous features larger than $2 \mu \mathrm{m}^{2}$ area, and the $5000 \times$ micrographs were processed to contain fine-scale porous features smaller than $2 \mu \mathrm{m}^{2}$ area. The porosity content obtained from both the fine-scale and coarse porosity was added to obtain total porosity.

\section{BC Surface Topography}

Two-dimensional surface topography of the BC was measured using a stylus-based surface profilometer, Surftest SJ301 (Mitutoyo Europe $\mathrm{GmbH}$, Germany) following ISO 4288 standard. On each BC sample, ten measurements were taken to obtain the average roughness $\left(R_{a}\right)$ values. 3D images of the BC surface were captured using SEM at 500x magnification. This method of 3D image capturing is only used for visualization, and it is not reliable for quantitative roughness measurements.

\section{Column Density Measurement}

The column density of SPS and PS-PVD TC samples was measured by using SEM micrographs taken at $200 \times$ magnification along the cross section of the coatings. Five SEM micrographs per coating were used to measure the column density. A straight line was drawn at the center of all the TC, and then, the number of vertical cracks that have a length greater than half of the coating thickness and also intersecting the line were counted. Equation 1 was used to calculate the column density (Ref 25).

\section{Thermal Conductivity Measurement}

Thermal conductivity was obtained from the thermal diffusivity which was measured using a Netzsch Laser Flash Apparatus LFA 427 system (Netzsch Gerätebau GmbH, Germany). Measurements were taken on coatings in the assprayed state at room temperature. Samples used for LFA measurement were prepared by water jet cutting 10-mmdiameter samples from the square plate. The samples were coated with a thin layer of graphite before the measurement to enhance the absorption by preventing direct transmission of infrared light pulse through the coating due to coating's transparency to the wavelength used in the laser flash experiment. As the laser pulse is fired at the substrate, it travels through the sample, leading to an increase in the temperature which is measured by InSb infrared detector. This signal is normalized and thus gives the thermal diffusivity according to Eq. 2 (Ref 27).

$\alpha=\frac{0.1388 L^{2}}{t_{(0.5)}}$

where $\alpha$ is the thermal diffusivity, $L$ is the thickness of the sample and $t_{(0.5)}$ is the time taken for the rear face temperature to reach one-half of its maximum rise. Five such measurements were taken for each sample.

A three-layer Cowan model (substrate $+\mathrm{BC}+\mathrm{TC}$ ) was used to measure the thermal diffusivity of the TC. The Cowan model considers the TC as an unknown layer in the system and BC and substrate as known layers. Specific heat capacity and thermal diffusivity used for Inconel 738LC were $0.419 \mathrm{~J} / \mathrm{g} \mathrm{K}$ and $3.5292 \mathrm{~mm}^{2} / \mathrm{s}$, respectively, for the $\mathrm{HVAF}$ bond coat, the values were $0.476 \mathrm{~J} / \mathrm{g} \mathrm{K}$ and $2.997 \mathrm{~mm}^{2} / \mathrm{s}$, respectively, whereas for VPS bondcoat, the values were $0.627 \mathrm{~J} / \mathrm{g} \mathrm{K}$ and $2.133 \mathrm{~mm}^{2} / \mathrm{s}$, respectively. These values were taken from earlier measurements taken on bare substrate and substrates with only BC based on separate investigations carried out by author's group. The calculation of thermal conductivity of the topcoat from its thermal diffusivity requires properties such as specific heat capacity and coating density. The specific heat capacity of

Column density $=\frac{(\text { No. of column boundaries intersecting the line }-1)}{\text { True length of the line }}$. 
YSZ was previously measured as $0.45 \mathrm{~J} / \mathrm{g}-\mathrm{K}$ (Ref 28). The density of YSZ topcoat was calculated using Eq 3.

$\rho a=\rho b(1-P)$

where $P$ is the porosity content of the coating, $\rho a$ is the apparent density and $\rho b$ is the bulk density of YSZ $(6.1 \mathrm{~g} /$ $\mathrm{cm}^{3}$ ) (Ref 29). Thermal conductivity $\lambda\left(\mathrm{W} \mathrm{m}^{-1} \mathrm{~K}^{-1}\right)$ was then mathematically calculated by using Eq 4 .

$\lambda=\rho a \cdot \alpha \cdot C_{p}$

where $C_{p}\left(\mathrm{~J} \mathrm{~kg}^{-1} \mathrm{~K}^{-1}\right)$ is the specific heat capacity (Ref 22).

\section{Thermal Cyclic Fatigue Lifetime}

TCF testing is an accelerated test performed to analyze the performance of TBCs under cyclic heating and cooling. Since the TCF test involves long exposure of the TBCs to high temperatures, significant oxidation of the $\mathrm{BC}$ can be observed, leading to the formation of the TGO layer. Due to the heating and cooling cycles, stresses are developed in the TBCs resulting from the difference in thermal expansion coefficients of different layers in the TBC system. The growth of the oxide layer and CTE mismatch of different layers are the main driving factors for the failure of TBCs in TCF testing. In this study, the TCF test was performed in an automated furnace (ENTECH ECF 14/16, Ängelholm, Sweden). The samples were heated in a furnace at $1100{ }^{\circ} \mathrm{C}$ for $1 \mathrm{~h}$ and then followed by rapid cooling to around $100{ }^{\circ} \mathrm{C}$ using compressed air for $10 \mathrm{~min}$. These heating and cooling steps make one complete cycle of the TCF test. When the cooling step is completed, the samples return to the furnace continuing to another cycle, and this continues until the failure is observed. After each cycle, a camera captures an image of the samples. The TBCs are considered to be failed when the spallation exceeds $20 \%$ of the coated surface. Three samples from each set of coatings were analyzed for the TCF lifetime.

\section{Burner Rig Tests}

Burner rig testing is used to mimic the complex thermomechanical loading in gas turbine environment in which temperature gradient conditions at elevated temperatures are coupled to cyclic heating and cooling at substantial transient rates. This allows to study both the temperatureinduced aging of each layer of the TBC systems at relevant temperatures and the impact of gradient conditions on the effective stress levels arising from CTE mismatches. During heating phase, the TC surface of button-type specimen was exposed to a $\mathrm{CH}_{4} / \mathrm{O}_{2}$ flame, while the backside of the substrate was cooled by pressured air. After each 5 min of heating, the gas burner was removed and the front surface is also cooled by pressured air, while the backside cooling is continued. After 2 min of cooling, the cycle was repeated until failure of the coating was testified if at least $30 \%$ of the coated area was spalled. Temperatures of the surface and of the substrate were monitored by means of a LWIR pyrometer and a thermocouple at substrate's center position, respectively. Fluxes in the gas burner and cooling nozzle were controlled to keep the surface temperatures at $1400{ }^{\circ} \mathrm{C}$ and the substrate temperature at the thermocouple position at $1050{ }^{\circ} \mathrm{C}$ during the heating dwell times. Heating and cooling from maximum temperature to temperatures below $50{ }^{\circ} \mathrm{C}$ and vice versa were achieved within the order of one minute. At the beginning of each cooling phase, an inversion state of the temperature gradient across the TC was achieved with the surface temperature well below the temperature at the $\mathrm{TC} /$ $\mathrm{BC}$ interface. The interface temperature at the TC/BC interface was calculated from logged readings of surface and substrate temperature by means of the one-dimensional heat flux approximation considering the thicknesses and the thermal conductivities of the TCs, the bond coat and the substrates. Two samples from each set of coatings were analyzed.

\section{Results and Discussion}

\section{Bondcoat Topography}

It is essential to analyze the surface topography of the BC to understand its effect on TCF lifetime and failure mechanisms. Different spraying processes inherit different surface topography and roughness to the BC (Ref 22). Figure 1 shows the $\mathrm{BC}$ surface profile (3D image) captured using SEM and the top view of the $\mathrm{BC}$, produced by HVAF and VPS. It can be seen that all three surfaces have unique and distinct surface features. The dark gray regions in Fig. 1(b) and (c) indicate the formation of alumina during the vacuum heat treatment, while the black regions indicate porosity. From Fig. 1(a) and (a-1), it can be noted that HVAF unpolished BC shows the presence of unmolten particles along with hemispherical hills uniformly spread throughout the BC surface as indicated by arrow marks. The reason behind this could be the low process temperature of HVAF, which leads to insufficient melting of larger particles and thus results in poor deformation of particles (Ref 30). The VPS BC surface is shown in Fig. 1(b) and (b1). From the 3D topography image, it can be seen that the surface has small sharp hills as indicated by arrows that are uniformly spread throughout the surface. The peaks and valleys on the surface of VPS BC (Fig. 1b-1) might be attributed to the splashing of completely molten particles in combination with the lower kinetic energy of the molten 

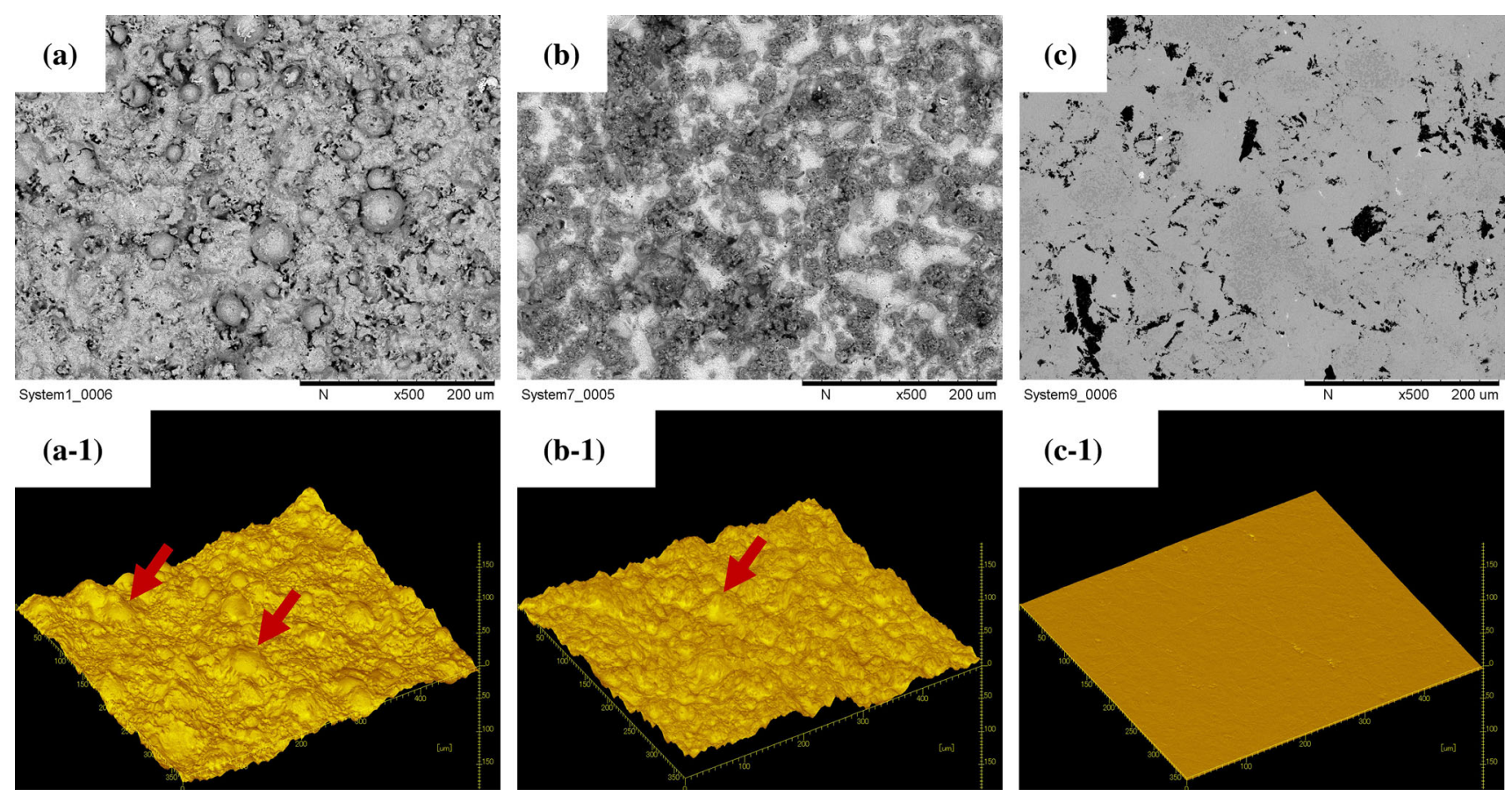

Fig. 1 Top-view SEM micrographs of BC sprayed by (a) HVAF, (b) VPS along with (c) HVAF polished and 3D profile showing the surface topography of BC, (a-1) HVAF, (b-1) VPS and (c-1) HVAF polished

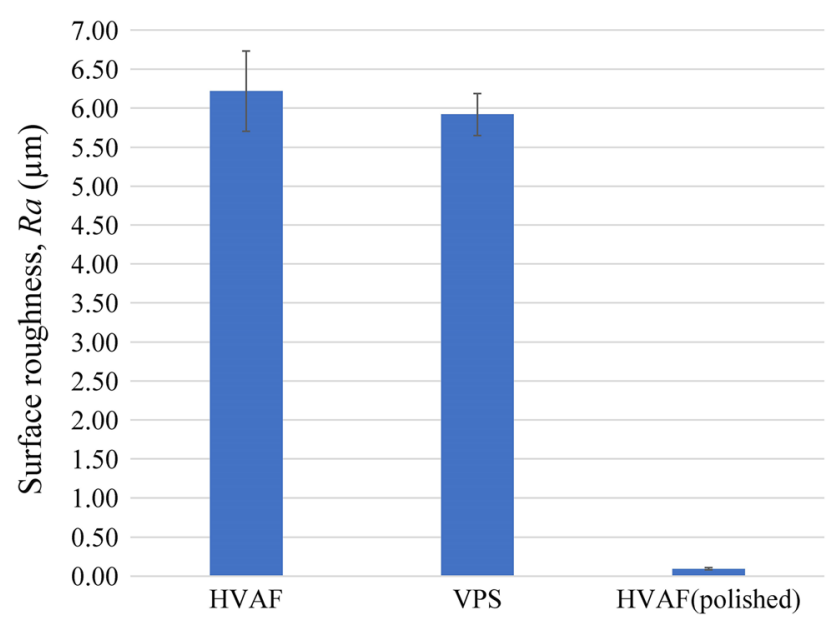

Fig. 2 Surface roughness of BC samples

particles in the VPS process (Ref 30). The PS-PVD TC deposition requires a smooth or polished BC surface because a rough $\mathrm{BC}$ surface could hinder the growth of homogeneous columnar microstructure. Thus, polishing of the HVAF BC was performed prior to deposition of PSPVD TCs. In case of HVAF-polished bondcoat shown in Fig. 1(c) and (c-1), near flat surface with very low roughness can be observed.

Figure 2 shows the surface roughness of the $\mathrm{BC}$, and it can be seen that the VPS- and HVAF-processed BCs have similar average roughness $\left(R_{a}\right)$ values, whereas the polished HVAF BC has a value close to $0.1 \mu \mathrm{m}$. It is to be noted that the $R_{a}$ value for HVAF and VPS BC is similar, but still the surface topography is different.

\section{Coating Microstructure}

The as-sprayed SEM micrographs of the cross section of all the coatings produced in this study are shown in Fig. 3. As expected, the TC produced by SPS, PS-PVD and APS processes shows different microstructural features. Broadly, it can be observed from Fig. 3(a), (b) and (d) that APS process results in the formation of a coating with lamellar microstructure, whereas the SPS and PS-PVD spraying process led to the formation of a coating with columnar microstructure. Figure 3(c), (e) and (g) shows typical SPS porous columnar microstructures, and Fig. 3(f) shows the SPS dense/vertically cracked microstructure. While spraying SPS dense TC, the spray distance and suspension feed rate was kept lower and the energy (power) supplied was comparatively higher than for SPS porous TC. Utilization of higher energy while spraying leads to strong atomization and the complete melting of the particles inside the plasma plume (Ref 31). Also, due to the lower spraying distance, the molten particles end up arriving at the substrate sooner at a very high velocity. This leads to a planar deposition structure that induces tensile stresses in the coatings. These tensile stresses are the main driving force in the vertical crack growth in the TC (Ref 25). PS-PVD process results in the formation of a quasicolumnar microstructure as depicted in Fig. 3(h) and (i). 

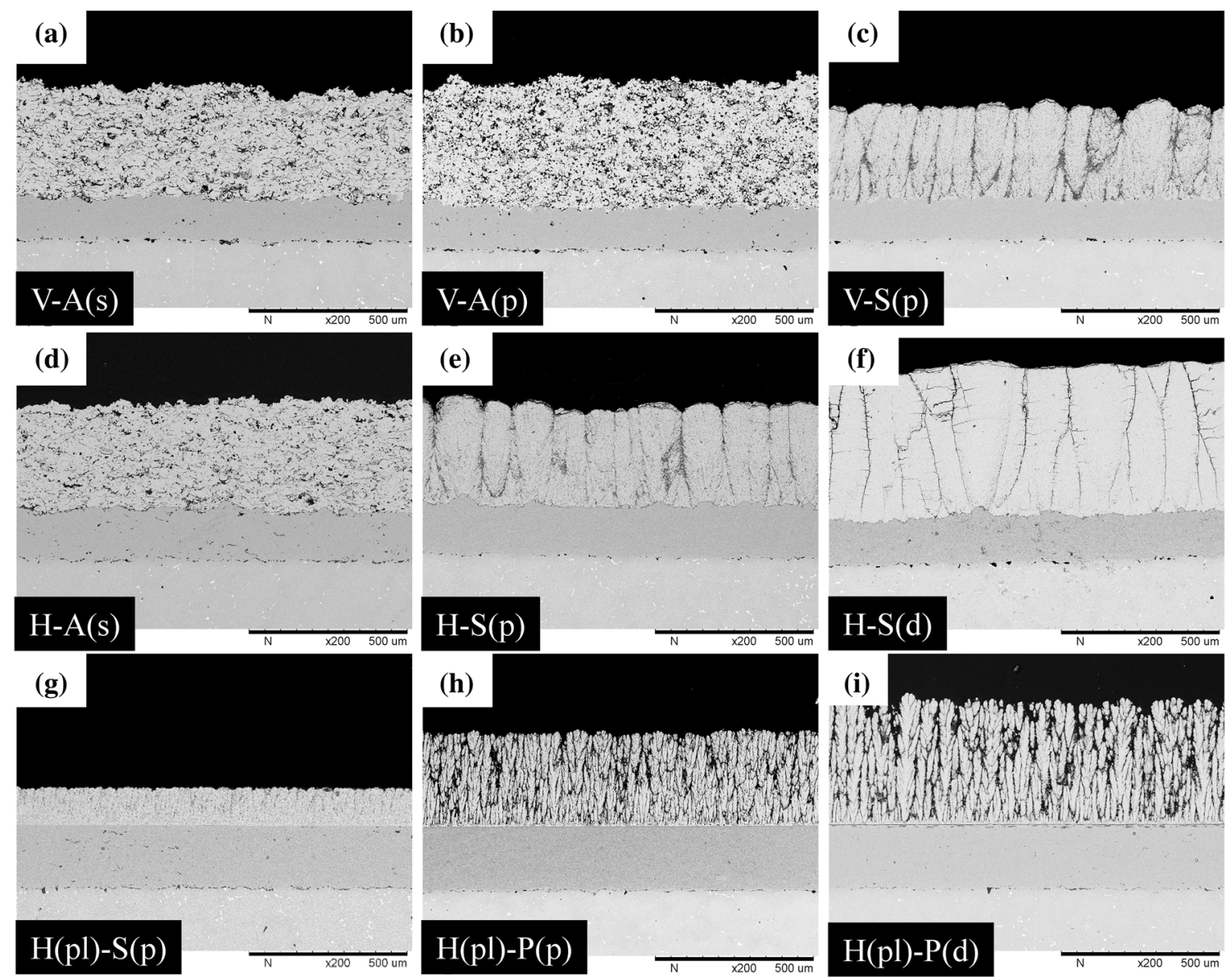

Fig. 3 As-sprayed SEM micrographs of the TBCs

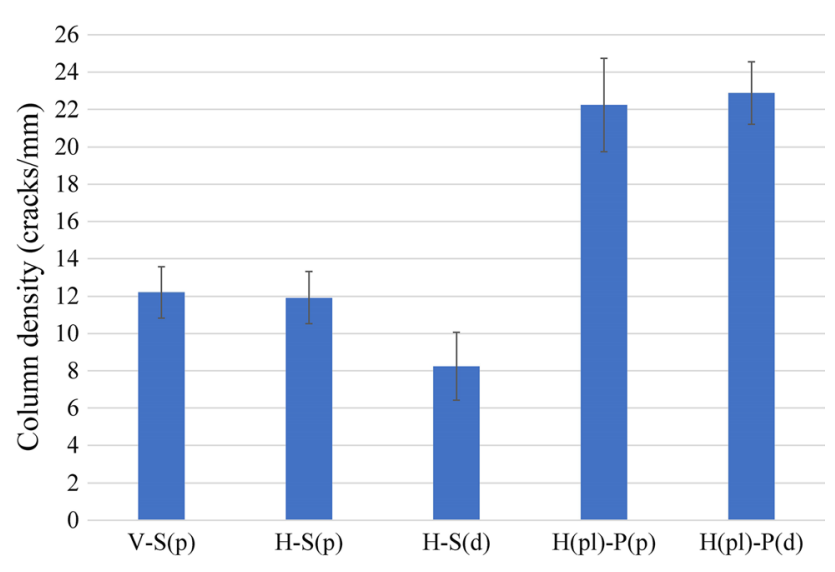

Fig. 4 Column density of the SPS- and PS-PVD-sprayed TCs

The columnar structure in PS-PVD consists of fine needlelike structures which is quite distinct to the columnar microstructure obtained by SPS. Both PS-PVD coatings were sprayed at the same net plasma power, however, with different plasma gas compositions, leading to different porosities in the columns, intercolumnar gaps and deposition efficiencies (Ref 32). The roughness of the polished
$\mathrm{BC}$ seemed to be too low for the particles to adhere to the surface in the SPS process, which resulted in the partial spallation of the $\mathrm{TC}$ from the $\mathrm{BC}$ during the spraying process. This indicates that too smooth surface may not be appropriate for SPS coating deposition and light grit blasting may be necessary to provide the required anchoring. Thus, $\mathrm{H}(\mathrm{pl})-\mathrm{S}(\mathrm{p})$ was excluded from the further characterization of TBCs in this study.

The column density of the SPS and PS-PVD TBCs is shown in Fig. 4. The difference in column density of the SPS TBCs can be attributed to the difference in TC deposition parameters. The higher column density of PSPVD TBCs can be attributed to their much narrower column width due to the different deposition process.

\section{Porosity Analysis}

The porosity of the coatings measured at two different scales is summarized in Fig. 5. It can be seen that fine porosity values for SPS porous TCs are higher than the rest of the coatings. Figure 6 shows the nano-sized and submicron pores that contribute to the fine porosity in SPS 
Fig. 5 Comparative distribution of porosity content at two different scales for all the TBCs

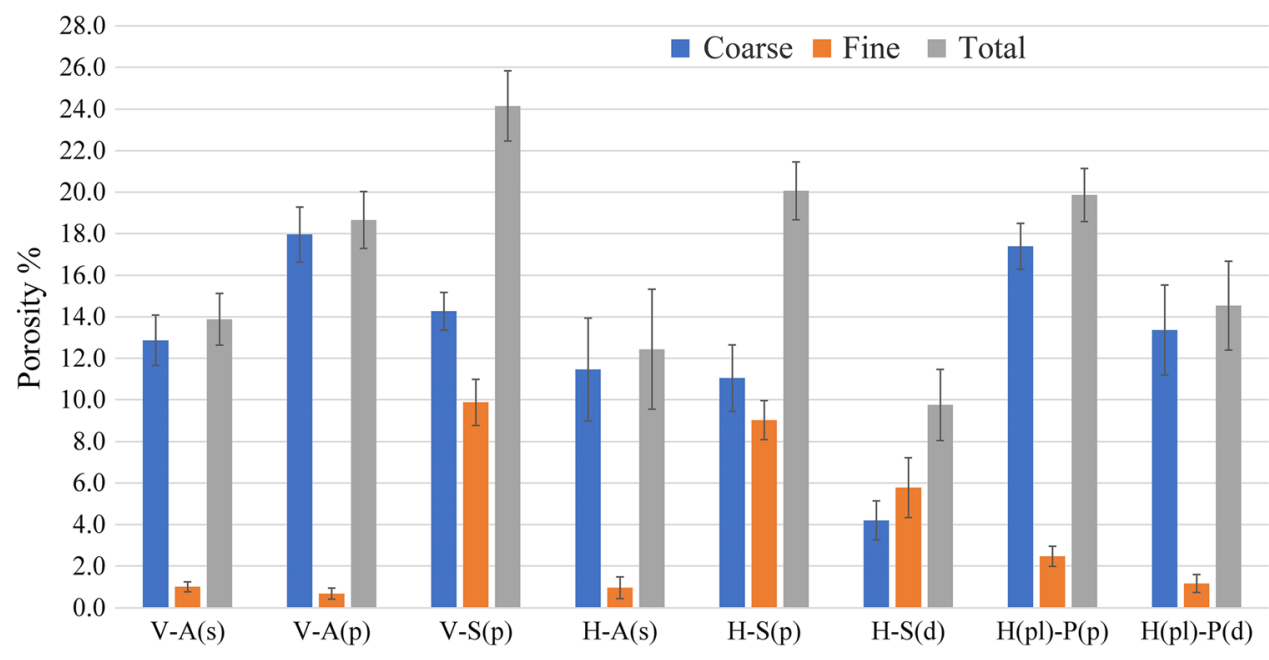

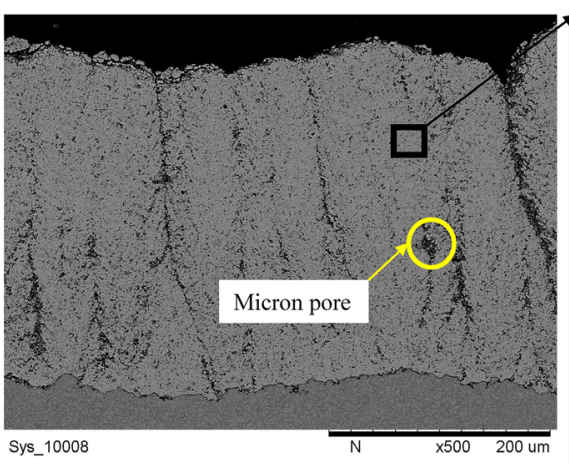
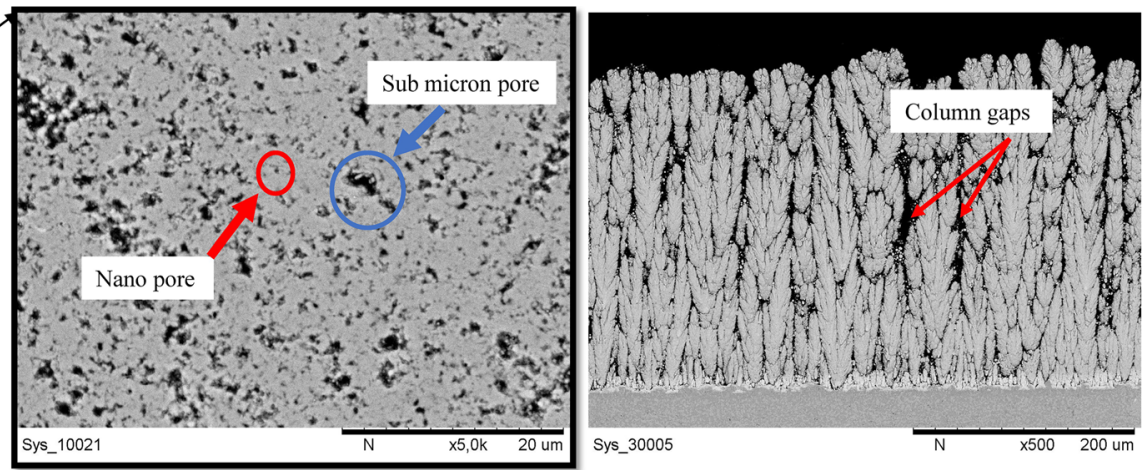

Fig. 6 Cross-sectional SEM micrographs showing microstructural features of coatings that contribute to coarse and fine scale of porosity (a) $\mathrm{H}-\mathrm{S}(\mathrm{p})$, (b) high-magnification SEM micrograph of $\mathrm{H}-\mathrm{S}(\mathrm{p})$, (c) $\mathrm{H}(\mathrm{pl})-\mathrm{P}(\mathrm{p})$

porous $\mathrm{TC}$ of $\mathrm{V}-\mathrm{S}(\mathrm{p})$ along with micron pores that contribute to coarse porosity. It can be observed that the total porosity content of $\mathrm{H}-\mathrm{S}(\mathrm{p})$ and $\mathrm{H}(\mathrm{pl})-\mathrm{P}(\mathrm{p})$ is same but when we compare the contribution of coarse and fine-scale porosity in the TBCs, significant variations can be observed in fine-scale porosity content. H-S(d) has shown to be the TBC with the least porosity content. The presence of uniform inter-pass porosity bands was observed in $\mathrm{H}-\mathrm{S}(\mathrm{d})$. The number of spraying passes directly corresponds to the interpass porosity bands across the coating (Ref 26). This shows the ability of the SPS process to produce submicron and nanoscale porosities as well as the ability to produce a very dense coating just by varying the spray process parameter. A detailed description of the effect of process parameters on the pore size distribution is discussed in previous investigations carried out by author's group (Ref 33).

In case of PS-PVD TBCs, the column gaps are the main contributing factor to the overall porosity as shown in Fig. 6. The difference between the fine-scale porosity in $\mathrm{H}(\mathrm{pl})-\mathrm{P}(\mathrm{p})$ and $\mathrm{H}(\mathrm{pl})-\mathrm{P}(\mathrm{d})$ does not seem to be much. The same is the case with APS TCs; the coarse porosity is mainly due to oblate spheroids and cracks (Ref 34 ). It has

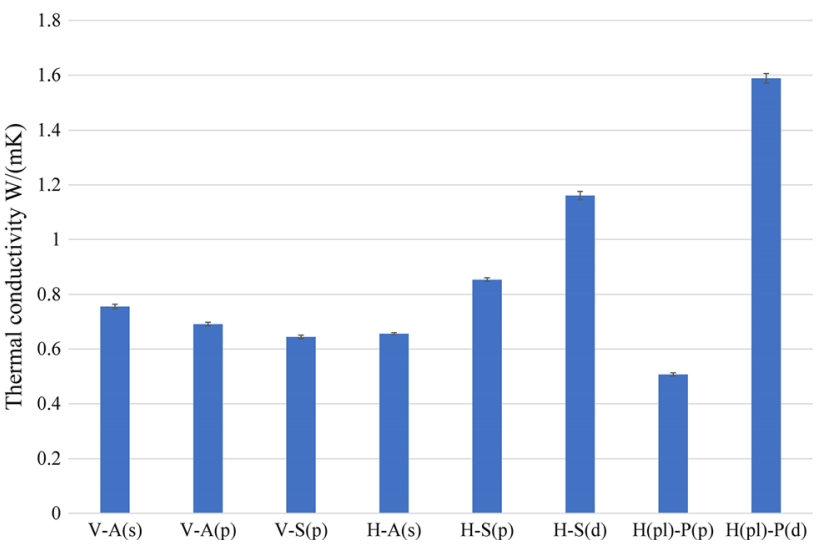

Fig. 7 Thermal conductivity values of the TBCs

to be stated here that the measurement techniques influence the results of porosity evaluation. This can be clearly seen in the APS coatings. Although high magnification is used and hence most of the fine features are probably detected, features as micro-cracks are added to the large-sized porosity regime. Mercury porosimetry results, for example, of the standard coating V-A(s) clearly show that a lot of 
submicron pores/cracks are present in the coatings (more than $50 \%$ of total porosity) (Ref 35$)$.

\section{Thermal Conductivity}

Figure 7 shows the thermal conductivity of the as-sprayed TBCs measured at room temperature. From Fig. 7, it is apparent that microstructural features of the TBCs strongly effect the thermal conductivity. Among all the TBCs in the study, $\mathrm{H}(\mathrm{pl})-\mathrm{P}(\mathrm{p})$ showed the lowest thermal conductivity $[0.5 \mathrm{~W} /(\mathrm{mK})]$, whereas $\mathrm{H}(\mathrm{pl})-\mathrm{P}(\mathrm{d})$ showed the highest thermal conductivity $[1.6 \quad \mathrm{~W} /(\mathrm{mK})] . \quad \mathrm{V}-\mathrm{S}(\mathrm{p})$ and $\mathrm{H}-\mathrm{S}(\mathrm{p})$ TBCs showed lower thermal conductivity than $\mathrm{H}-\mathrm{S}$ (d) due to its porous columnar microstructure compared to the dense vertically cracked microstructure in $\mathrm{H}-\mathrm{S}(\mathrm{d})$. Also, between $\mathrm{V}-\mathrm{S}(\mathrm{p})$ and $\mathrm{H}-\mathrm{S}(\mathrm{p}), \mathrm{V}-\mathrm{S}(\mathrm{p})$ has lower thermal conductivity owing to its higher porosity content topcoat formed due to the different roughness profile of VPS bondcoat as observed in previous work (Ref 30). It was discussed in earlier studies that the thermal conduction in zirconia is mainly by lattice vibrations (phonons) or by radiation (photons) (Ref 38). The radiation heat transfer is significant only at high temperatures (>1000 K) (Ref 39). Since all the measurements were taken at room temperature, the prime mode of heat transfer is by phonon conduction. As mentioned earlier, in APS TBCs the lamellar microstructure has porosity content mainly contributed from intra-splat globular pores and cracks that exists between the flatten lamellae. These features in APS TBCs interrupt the phonon conduction by scattering the phonons. In SPS coatings, the wide range (fine scale and coarse) of porosity content affects the thermal conductivity as heat flux is not possible through the pore volume (Ref 29). Thus, the lower thermal conductivity values of SPS porous and APS TBCs can be attributed to their microstructural features as discussed above. It

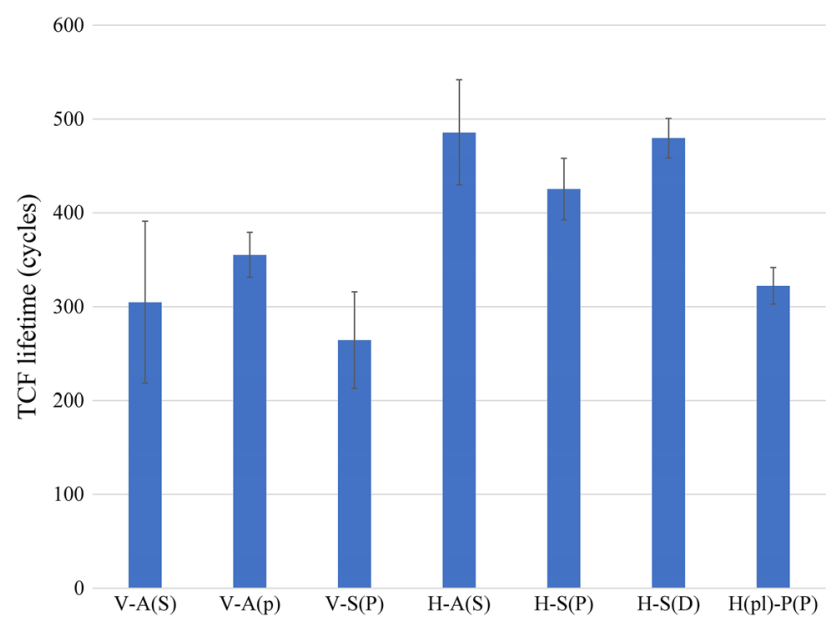

Fig. 8 TCF lifetime of TBCs is interesting to note that the porous APS coating does not influence the thermal conductivity values radically. It might be related to the higher amount of fine micro-cracks in the standard coatings, which more effectively reduces thermal conductivity than globular pores. H-S(d), i.e., SPS dense coating, showed thermal conductivity of around 1.16 $\mathrm{W} /(\mathrm{mK})$, which can be attributed to its denser microstructure, as lower-porosity content results in lower phonon scattering interfaces and thus leads to increased thermal conductivity. The high thermal conductivity of $\mathrm{H}(\mathrm{pl})-\mathrm{P}(\mathrm{d})[1.6 \mathrm{~W} /(\mathrm{mK})]$ can be attributed to its low porosity level that is mainly contributed by coarse porosity and almost negligible fine porosity, leading to a higher thermal conductivity.

\section{Thermal Cyclic Fatigue Lifetime}

The TCF results are summarized in Fig. 8. As mentioned earlier that the failure criteria in this study were $20 \%$ spallation of TC. In case of $\mathrm{H}(\mathrm{pl})-\mathrm{P}(\mathrm{d})$, the testing was stopped after around 1800 cycles, as the substrate started to deform due to severe oxidation before the TBC could fail. It is noteworthy that, except for $\mathrm{H}(\mathrm{pl})-\mathrm{P}(\mathrm{p})$ with polished HVAF BC, all samples with HVAF BC showed better lifetime than with VPS BC.

There could be various reasons for failure during TCF test such as TGO growth rate, TC-BC interface topography and TC microstructure (Ref 30). Figure 9 shows the crosssectional SEM micrographs of failed samples, comparing HVAF and VPS BC along with their respective TGO layer. From Fig. 9, it can be seen that the TGO layer is much thicker and has more uneven growth in case of TBC with VPS BC, V-A(s), when compared to the coating with HVAF BC, H-A(s). In earlier studies, it has been clearly demonstrated that a too clean processing of the $\mathrm{BCs}$ (as it might be in VPS) might lead to an excess amount of free reactive elements such as $\mathrm{Y}$ which is detrimental for the performance (Ref 40). This is underlined by the much higher oxygen content in the HVAF coatings ( $\sim 3600 \mathrm{ppm})$ compared to the VPS coatings (typically $800 \mathrm{ppm}$ ). In high-velocity APS BC, a similar effect could be demonstrated (Ref 41). A slow growing, dense and more uniform layer of TGO can be seen in the case of H-A(s) which could potentially prevent the $\mathrm{BC}$ from further oxidation. The dark gray phase in Fig. 9(a) and (b) shows the remaining $\beta$-phase in HVAF and VPS BC as indicated. The amount of $\beta$-phase that is remaining in the $\mathrm{BC}$ indicates the alumina reserve present in the $\mathrm{BC}$ necessary for aluminum oxide layer formation. The $\beta$-phase content gradually decreases as the oxidation of $\mathrm{BC}$ continues. At some point, when the $\beta$-phase in the $\mathrm{BC}$ completely depletes, there is no further formation of the protective alumina oxide layer possible. Instead, rapid oxidation of other constituents such 
Fig. 9 SEM micrographs of failed TCF samples showing the $\mathrm{BC}$ and TGO layer of (a), (a-1) $\mathrm{V}-\mathrm{A}(\mathrm{s})$ and (b), (b-1) H-A(s)
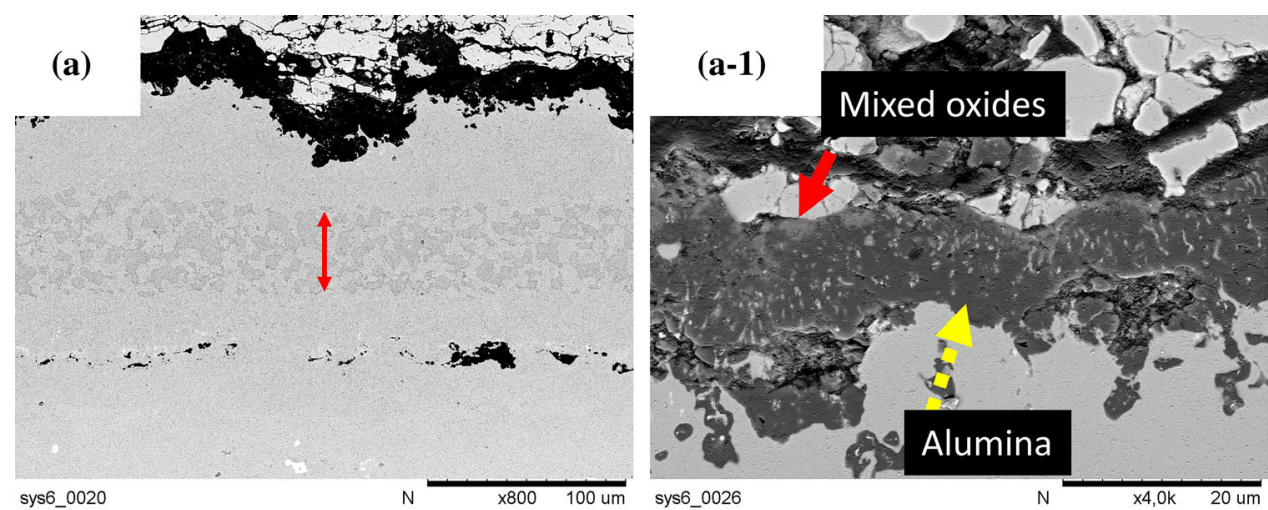

(b)
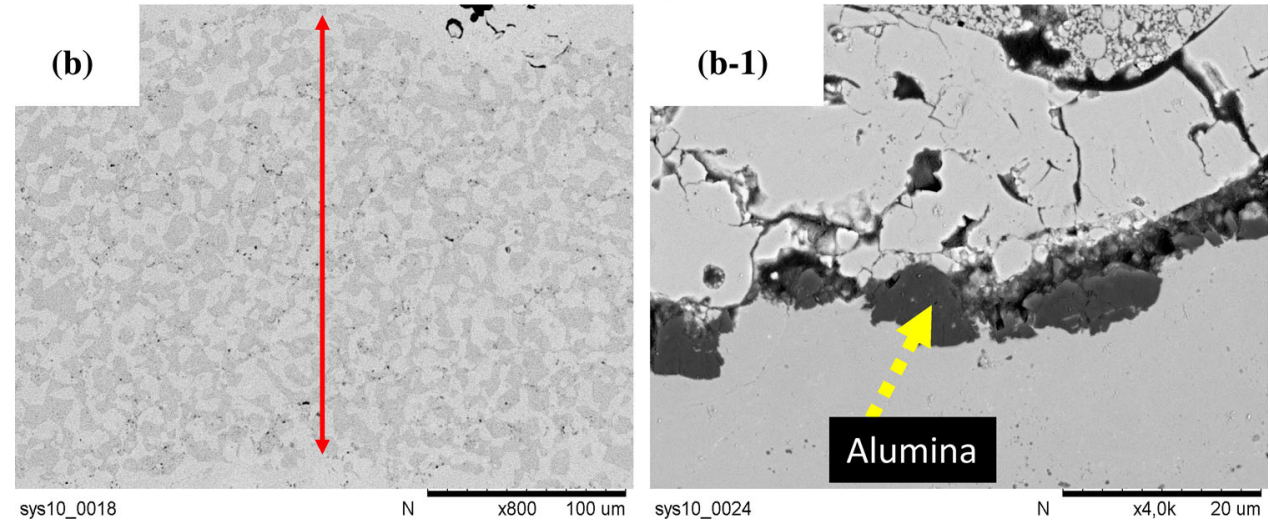

as nickel and chromium in the $\mathrm{BC}$ begins appearing as a light gray color in SEM, indicated by solid arrow mark in Fig. 9(a-1) (Ref 42). The mixed oxides tend to grow rapidly and generate additional stresses near the interface, resulting in failure of TBCs. The dashed arrow marks in Fig. 9 indicate alumina oxide (TGO) layer appearing as dark gray color in SEM. Thus, it can be said that the HVAF BC tends to delay the formation of detrimental mixed oxides by forming a thin and uniform slow growing alumina oxide layer by avoiding over-doping effects in the bond coats

Figure 10 shows the SEM micrographs of cross section of the failed TBC samples after TCF testing. Vertical cracks can be seen in the TCs of V-A(p), V-S(p) and $\mathrm{H}-\mathrm{S}(\mathrm{p})$ in Fig. 10. Horizontal crack propagating through the PS-PVD porous TC can be observed. It should be noted that the TC in case of $\mathrm{H}(\mathrm{pl})-\mathrm{P}(\mathrm{d})$ detached from the $\mathrm{BC}$ during the sample preparation and not due to failure.

It is to be noted that the first few layers in the TC of $\mathrm{H}(\mathrm{pl})-\mathrm{P}(\mathrm{p})$ were the prime area where failure had occurred. The reason for this failure mechanism is deemed to be the initial relatively dense layer formed retarding the columnar growth due to the spraying conditions, as discussed in more detail in Sect. 3.6. The vertically cracked microstructure of $\mathrm{H}-\mathrm{S}(\mathrm{d})$ coating shows the presence of horizontal cracks that seems to be propagating through the inter-pass porosity bands present in the TC as shown in Fig. 11. From Fig. 8, it can be observed that $\mathrm{H}-\mathrm{A}(\mathrm{s})$ and $\mathrm{H}-\mathrm{S}(\mathrm{d})$ showed the highest lifetime among the failed samples. It was demonstrated by Dwivedi et al. that the fracture toughness of TBCs depends upon porosity content, material composition and microstructure (Ref 36). Zhou et al. also showed that for SPS TBCs (Ref 37). In general, it is observed that as the porosity increases, the hardness and fracture toughness decrease. The high lifetime values might be correlated with the high fracture toughness of both the coatings as higher fracture toughness inhibits the tendency of crack propagation through the TBCs. The porous APS TBC, V-A(p), showed higher average lifetime than the standard reference APS TBC, V-A(s). As the failure occurred at the TC-BC interface, it is not surprising that the TGO growth plays a major role in the failure of the investigated TBCs.

Long exposure of the ceramic TC to high temperatures could lead to excessive sintering of the coatings. In APS TBCs, sintering promotes the closure of pores and cracks and thus reduces the overall porosity of the coating, which could lead to increased thermal conductivity (Ref 25) and considerable stiffening and hence stress increase (Ref 43). In the case of SPS TBCs, the sintering of the fine particles leads to the densification of pores and shrinkage of columns, which in turn leads to increased intercolumnar gaps (Ref 44). This could result in an increase in their thermal conductivity (Ref 42). Figure 11 shows the higher-magnification SEM micrographs of the failed TBCs. Sintering phenomenon is considered as an outcome of diffusion 

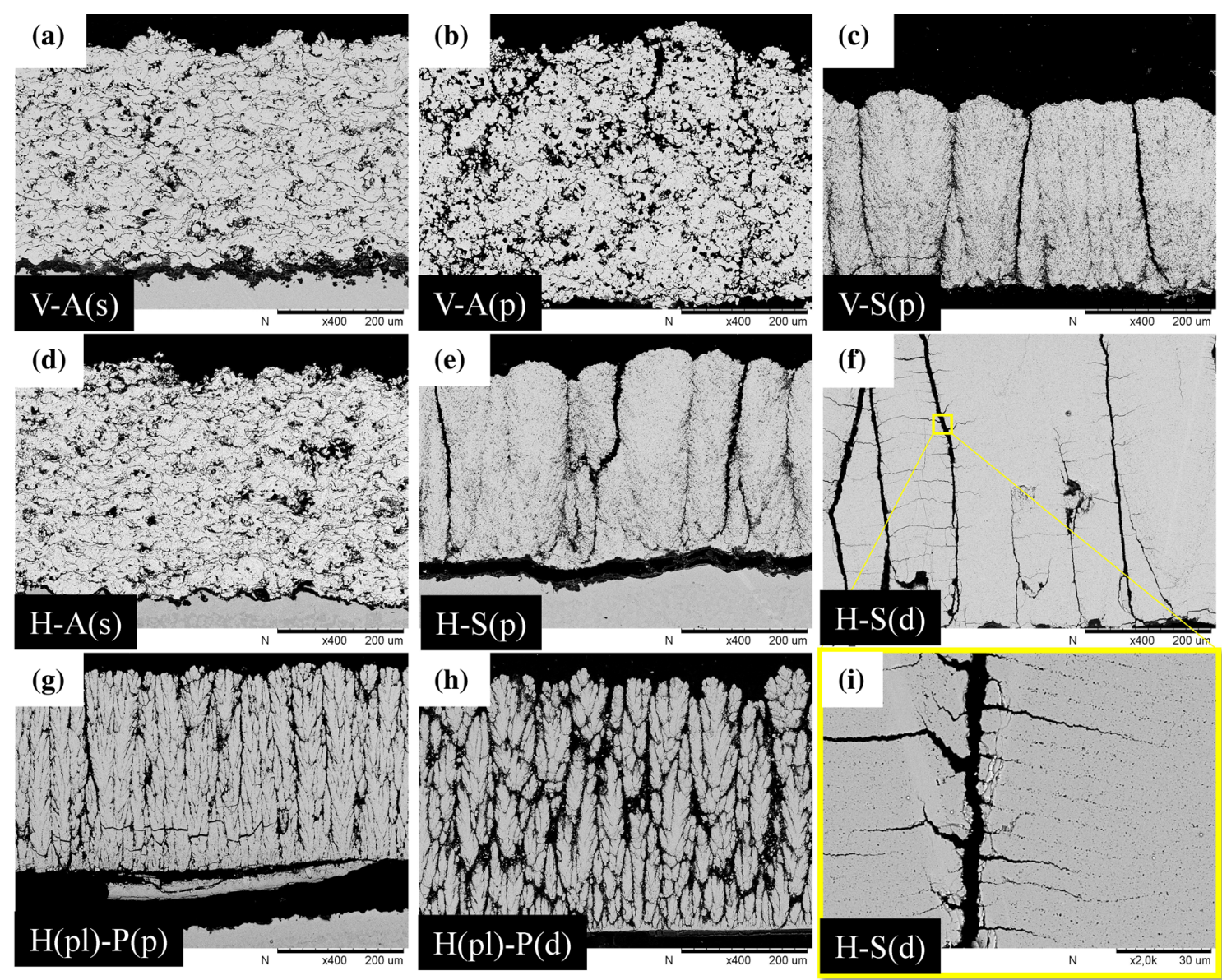

Fig. 10 Cross-sectional SEM micrographs of failed TBC samples from TCF test, (a) V-A(s), (b) V-A(p), (c) V-S(p), (d) H-A(s), (e) H-S(p), (f) $\mathrm{H}-\mathrm{S}(\mathrm{d})$, (g) $\mathrm{H}(\mathrm{pl})-\mathrm{P}(\mathrm{p})$, (h) $\mathrm{H}(\mathrm{pl})-\mathrm{P}(\mathrm{d})$, (i) magnified image of $\mathrm{H}-\mathrm{S}(\mathrm{d})$

process (Ref 45). It can be recognized from the shape of pores, as the material around the pores redistributes and results in a pore re-arrangement from facetted to more spherical in shape. This phenomenon can be seen in the investigated TBCs from the SEM cross section when compared to as-sprayed condition. No such changes were observed in case $\mathrm{H}-\mathrm{S}(\mathrm{d})$, as the dense SPS TBCs are already more resistant to sintering due to the dense microstructure. Since there was no spallation of the coating in case of $\mathrm{H}(\mathrm{pl})-\mathrm{P}(\mathrm{d})$, the fracture view was not taken.

\section{Burner Rig Tests}

In Fig. 12, the results of the burner rig tests for the different systems are shown. As explained in experimental section, the temperature in the middle of the substrate as well as the surface temperature is measured and the $\mathrm{BC}$ temperatures are calculated using the thermal conductivity from the measurements in Fig. 7. Indicated by gray shading is the lifetime range of a reference system of type V-A (different APS feedstock) derived from regression of six test results and the corresponding error band width, which is regularly used as laboratory standard in burner rig testing (Ref 46). As TC degradation is strongly influenced by thermally activated processes such as TGO growth and sintering, an Arrhenius-type behavior on interface temperature is typically observed. The samples V-A(s) showed lifetimes of 1037 and 1127 cycles. The more porous coatings V-A(p) had similar lifetimes of 915 and 1040 cycles. So, the increased porosity levels that are known to affect the mechanical properties such as Young's modulus and fracture toughness astonishingly do not lead to a significant lifetime increase. A reason could be the interaction of different failure mechanisms such as sintering, TGO growth and phase transformation (Ref 35). In contrast, the system H-A(s) revealed significantly longer lifetimes of 1661 and 1746 cycles. These results are similar as found in the TCF tests. In Fig. 13, the microstructures of the different APS coatings at the BC-TC interface are shown. Obviously, the TGO in the VPS TBCs is considerably thicker than in the HVAF coatings although the time at temperature was shorter for the VPS TBCs. The reasons are already discussed in Sect. 3.6. It is therefore assumed that in the burner rig tests also, the slower TGO growth led to 

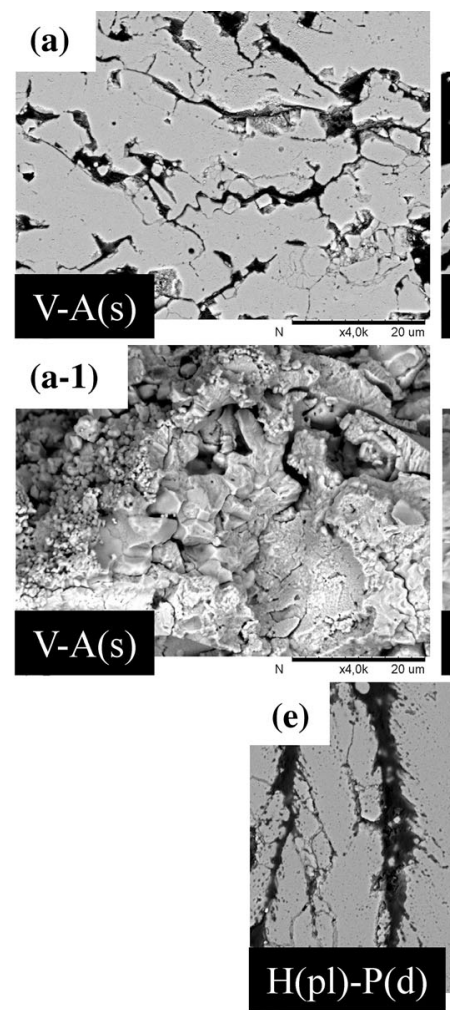
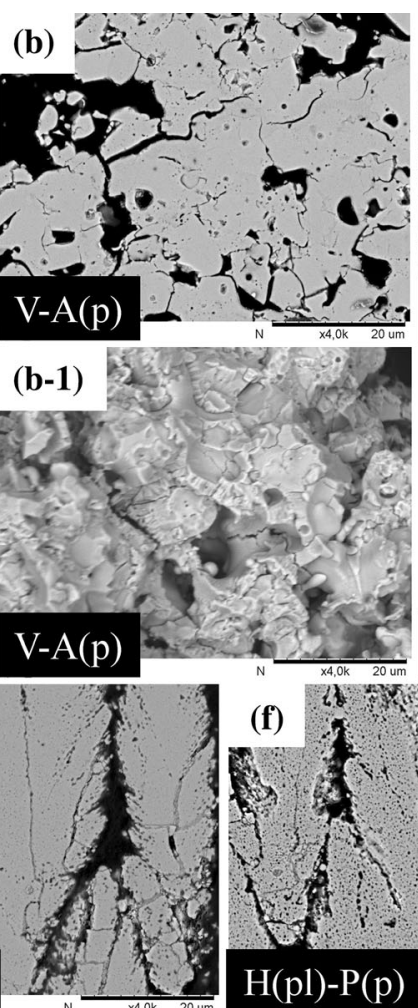

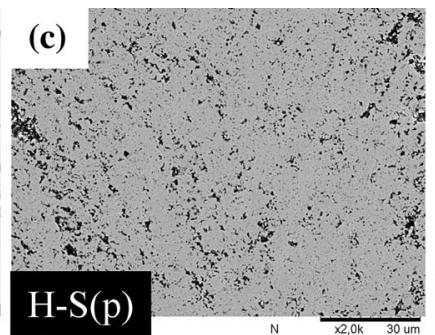

(d)

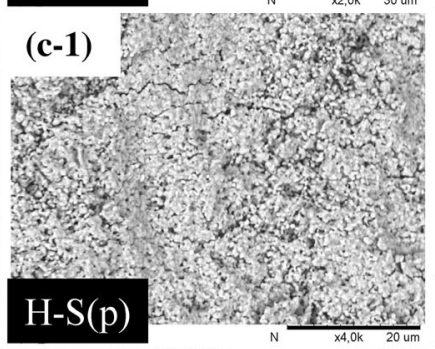

\section{$\mathrm{H}-\mathrm{S}(\mathrm{d})$}
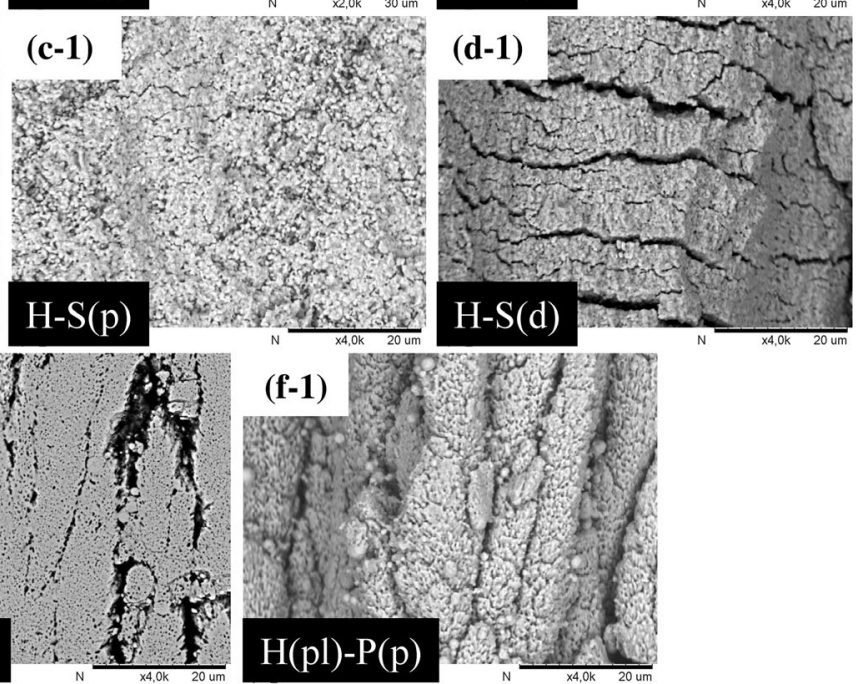

Fig. 11 Higher-magnification SEM cross section of TCF-failed TBCs (a) V-A(s), (b) V-A(p), (c) V-S(p), (d) H-S(d), (e) H(pl)-P(d) and (f) $\mathrm{H}(\mathrm{pl})-\mathrm{P}(\mathrm{p})$ and fracture view of TCF-failed TBCs (a-1) V-A(s), (b-1) V-A(p), (c-1) V-S(p), (d-1) H-S(d), (e-1) H(pl)-P(d) and (f-1) H(pl)-P(p)

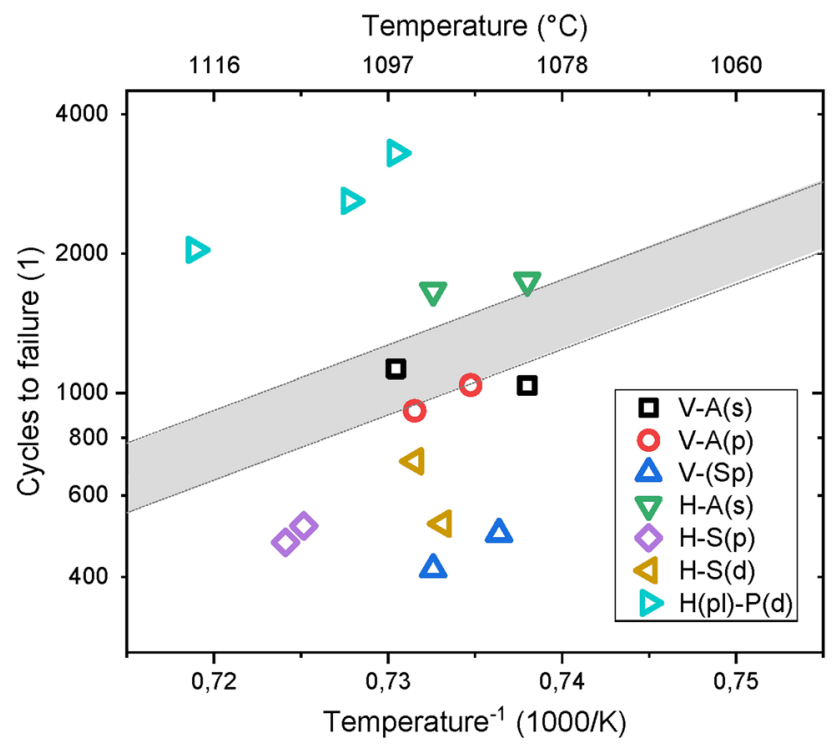

Fig. 12 Cycles to failure as a function of the average temperature at the TGO level calculated from surface/substrate temperatures logged throughout the steady-state period of heating phases in burner rig experiments

the increased lifetime of the HVAF systems. In Fig. 13, the results of the SPS systems are also shown. The major results are the considerably reduced lifetimes of the SPS systems compared to the APS systems. As discussed by
Zhou et al., it is assumed that the specific microstructure related to the growth mechanism of the SPS columns leads to an easier crack propagation at the interface (Ref 47). In Fig. 13(d)-(f), the microstructures at the BC-TC interface of the failed SPS samples are shown. Compared to the APS coatings, the TGOs are rather thin which is correlated with the reduced lifetime and the lower resistance to crack propagation.

Although there is an explanation for the reduced lifetime of the SPS samples in the burner rigs, it remains the question why the TCF lifetimes of the SPS samples are similar to the ones of the APS coatings. There are three major differences between the burner rig and the furnace tests. Firstly, the burner rig establishes a gradient throughout the TBC system. The higher surface temperature may introduce significant sintering. However, as the columns should open at elevated temperatures, the columns probably will not sinter together. In contrast, it is even found that the spacing between the columns increases. The second difference is the fast cooling and heating. These transient loadings can generate higher energy release rates than the isothermal tests (Ref 35). It is assumed that this high thermo-mechanical loading in combination with the third difference, the short cycle lengths, leads to earlier failure of the SPS coatings. This is also supported by the observation that the lifetime of the V-S(p) system is only 

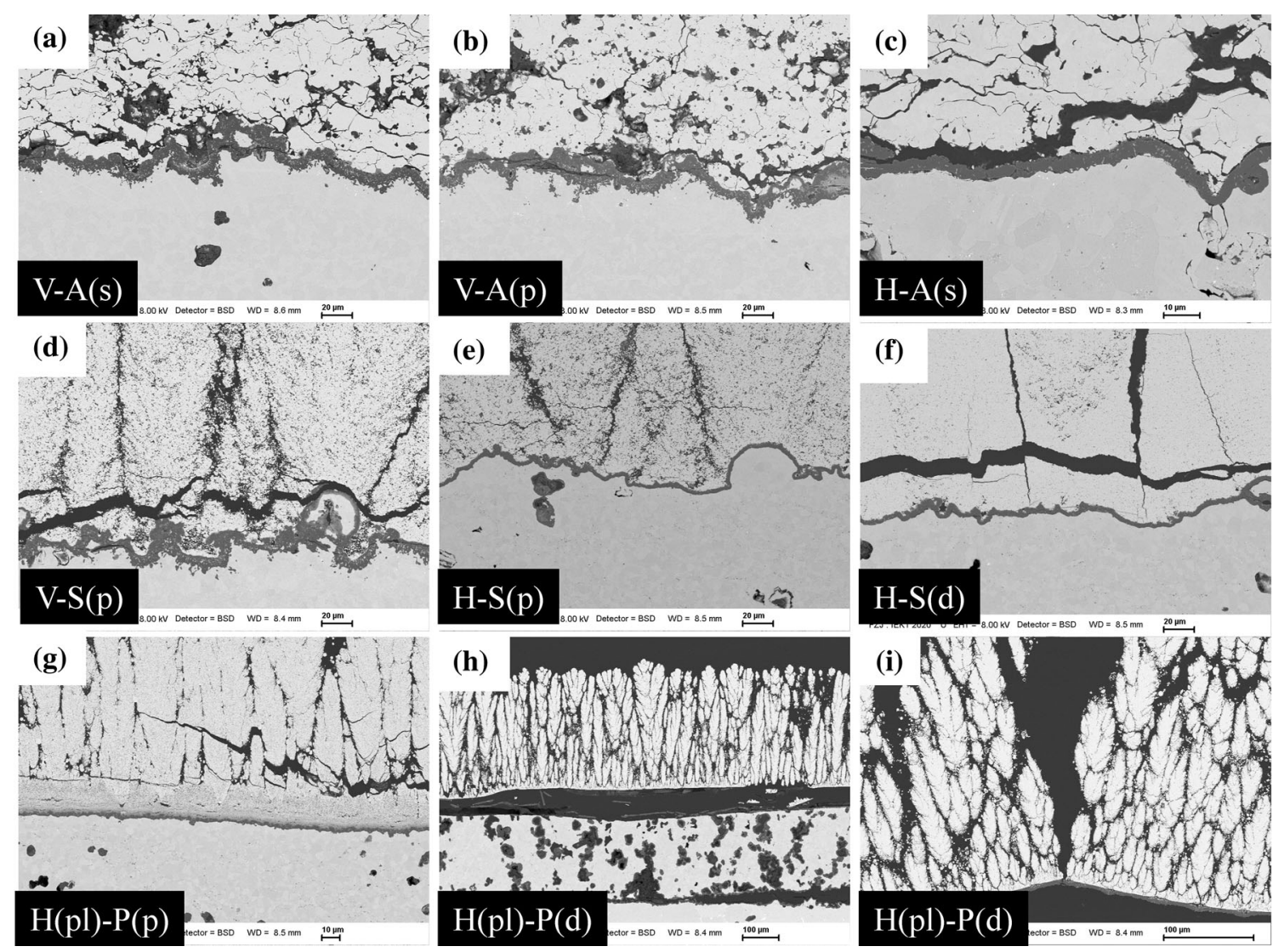

Fig. 13 SEM micrographs of the cycled samples: (a) V-A(s), (b) V-A(p), (c) H-A(s), (d) V-S(p), (e) H-S(p), (f) H-S(d), (g) H(pl)-P(p), (h, i) $\mathrm{H}(\mathrm{pl})-\mathrm{P}(\mathrm{d})$

insignificantly lower than that of the H-S(p) while showing significantly higher TGO thickness. This may indicate that the influence of the TGO thickness on the crack driving stresses in the burner rig experiment is less pronounced than in the TCF, or the stress peaks within the TC during the transients have major impact (Ref 47). Detailed finite element calculations will be done to get further insight in the failure mechanisms.

Similar to results in TCF testing, the performance of PSPVD TCs turned out to be very different. While H(pl)$\mathrm{P}(\mathrm{d})$ demonstrated outstanding cyclic life, the specimen of system $\mathrm{H}(\mathrm{pl})-\mathrm{P}(\mathrm{p})$ failed within less than 200 cycles. While depositing the TCs of the $\mathrm{H}(\mathrm{pl})-\mathrm{P}(\mathrm{p})$ system, the onset of columnar growth was retarded. Initially, a relatively dense layer was formed showing clear indications that $\mathrm{BC}$ elements diffused into it, as shown in Fig. 13(g). Although the columns were porous as single coating passes could be distinguished, the resulting low thermal conductivity did not result in beneficial lifetimes. The burner rig test was carried out at a surface temperature of $1270{ }^{\circ} \mathrm{C}$, while the calculated $\mathrm{BC}$ temperature was $1062{ }^{\circ} \mathrm{C}$. A higher surface temperature could not be properly adjusted because the TC thickness was only $300 \mu \mathrm{m}$. After burner rig test, fatal crack formation was observed in the columns above the dense layer. There are also some cracks along the TGO; however, apparently these did not lead to the failure of the sample. In contrast, the onset of columnar growth in the $\mathrm{H}(\mathrm{pl})-\mathrm{P}(\mathrm{d})$ system was immediately at the BC interface, as shown in Fig. 13(h). There was no indication of interdiffusion. The columns were denser than in the $\mathrm{H}(\mathrm{pl})$ $\mathrm{P}(\mathrm{p})$ system since single coating passes could not be distinguished. The parameters of the burner rig test were $1296{ }^{\circ} \mathrm{C}$ surface temperature and $1096{ }^{\circ} \mathrm{C}$ calculated BC temperature. The TC thickness was $330 \mu \mathrm{m}$. After burner rig test, fatal crack formation was observed at the TGO interface due to vast $\mathrm{Al}$ depletion of the $\mathrm{BC}$, leading to internal oxidation and pore formation, as the $\mathrm{H}(\mathrm{pl})$ $\mathrm{P}(\mathrm{p})$ was tested at increased $\mathrm{BC}$ temperature and $\mathrm{H}(\mathrm{pl})$ $\mathrm{P}(\mathrm{d})$ failed after a very long lifetime. As a result, the TGO separated from the $\mathrm{BC}$, partly the $\mathrm{BC}$ is even stripped from the substrate. The ceramic TC did not spall off completely as it was obviously very compliant, as shown in Fig. 13(i), as reported for such kind of columnar coatings already in (Ref 13). 
(a)

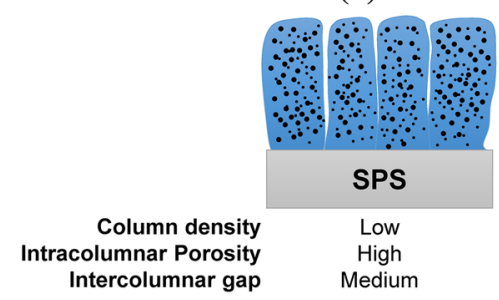

(b)

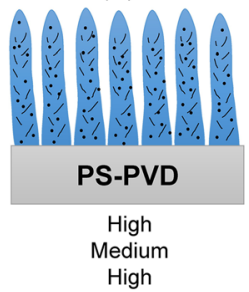

(c)

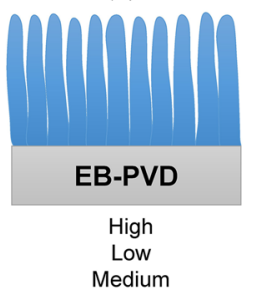

(d)

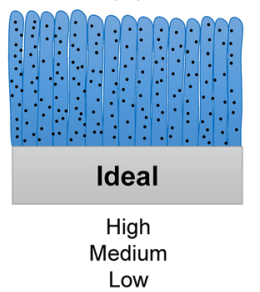

Fig. 14 A schematic showing the features of a typical columnar microstructure produced by (a) SPS, (b) PS-PVD and (c) EB-PVD. (d) An ideal columnar microstructure exhibiting both low thermal conductivity and high cyclic lifetime

\section{Design of Columnar Microstructure}

The focus of this work has been to investigate the performance of different columnar microstructures produced by SPS and PS-PVD and design an ideal columnar microstructure that shows a combination of relatively low thermal conductivity and high cyclic lifetime. The results in Sect. 3 show that while both processes can produce columnar microstructures similar to EB-PVD, the microstructural characteristics vary a lot. Figure 14 shows the typical differences among the columnar microstructural features in a coating deposited by SPS, PS-PVD and EBPVD in terms of column density, intracolumnar porosity and intercolumnar gap. While SPS coatings typically show high intracolumnar porosity, resulting in lower thermal conductivity, the high column density and medium intercolumnar gaps result in lower strain tolerance. PS-PVD columnar structures typically show wide intercolumnar gaps with high column density improving their strain tolerance, but show high thermal conductivity due to their porosity levels and wide intercolumnar gaps. EB-PVD coatings also have high column density but low intracolumnar porosity, resulting in even better strain tolerance and fracture toughness, but at the cost of higher thermal conductivity.

An ideal columnar microstructure, shown in Fig. 14(d), would thus have a combination of these features. The desired features in this structure would be high column density, medium intracolumnar porosity and narrow intercolumnar gaps providing the ideal combination of low thermal conductivity and high lifetime due to high strain tolerance and fracture toughness. It should be noted that the BC and TC-BC interface would need to be optimized appropriately in order to achieve high lifetime.

Achieving this ideal microstructure could of course be challenging and may not be technically feasible. Efforts have been made in previous works on TBCs produced by SPS by shot peening and grit blasting the BC surface resulting in a columnar microstructure with higher column density ( $\sim 25$ columns/mm as compared to $\sim 12$ columns/ $\mathrm{mm}$ in this study) resulting in dramatic improvements in
TCF lifetime (Ref 48). Further tests need to be performed in order to assess their full potential.

\section{Conclusions}

In this study, nine different sets of TBCs with TCs produced by SPS, PS-PVD and APS and BCs produced by HVAF and APS were investigated. The TBCs were characterized in terms of microstructural features, thermal conductivity, TCF and burner rig lifetime. The SPS TCs showed lower column density as compared to PS-PVD TCs. While both processes produced coatings with similar total porosity levels, the PS-PVD TCs showed much lower amount of fine porosity due to their denser columns with wider intercolumnar gaps. The dense PS-PVD TBC showed the highest cyclic lifetime in both TCF and burner rig testing due to its highly strain-tolerant microstructure, though it also showed the highest thermal conductivity among all samples. It was also observed that between the HVAF and VPS BCs, HVAF BC showed a lower oxidation rate and thus could improve the cyclic lifetime of TBCs.

Based on these results and previous findings, an ideal columnar TC microstructure was proposed that could exhibit both low thermal conductivity and high cyclic lifetime. This microstructure would consist of high column density, medium intracolumnar porosity and narrow intercolumnar gaps as compared to typical columnar microstructures produced by SPS, PS-PVD and EB-PVD.

Acknowledgments This work was supported by the Helmholtz Association, Germany, and the Knowledge Foundation, Sweden. The authors would like to thank Mr. F. Kurze and Mr. R. Laufs for performing the plasma spraying experiments and Mr. M. Tandler for carrying out the thermal cycling tests. The authors also acknowledge the SEM characterization. The authors acknowledge also funding from the Deutsche Forschungsgemeinschaft (DFG) via the project VA 163/8. In addition, the authors gratefully acknowledge the SEM analysis by Dr. Doris Sebold. The authors would also like to thank Mr. Stefan Björklund for the HVAF and SPS spraying at University West.

Funding Open access funding provided by University West. 
Open Access This article is licensed under a Creative Commons Attribution 4.0 International License, which permits use, sharing, adaptation, distribution and reproduction in any medium or format, as long as you give appropriate credit to the original author(s) and the source, provide a link to the Creative Commons licence, and indicate if changes were made. The images or other third party material in this article are included in the article's Creative Commons licence, unless indicated otherwise in a credit line to the material. If material is not included in the article's Creative Commons licence and your intended use is not permitted by statutory regulation or exceeds the permitted use, you will need to obtain permission directly from the copyright holder. To view a copy of this licence, visit http://creativecommons. org/licenses/by/4.0/.

\section{References}

1. X.Q. Cao, R. Vassen and D. Stoever, Ceramic materials for thermal barrier coatings, J. Eur. Ceram. Soc., 2004, 24(1), p 1-10.

2. Khan AS, Nazmy M. MCrAlY bond coating and method of depositing said MCrAlY bond coating. Google Patents (2007)

3. H.E. Evans and M.P. Taylor, Oxidation of high-temperature coatings, Proc. Inst. Mech. Eng. Part G J. Aerosp. Eng., 2006, 220(1), p 1-10.

4. G.W. Goward, Progress in coatings for gas turbine airfoils, Surf. Coat. Technol., 1998, 108, p 73-79.

5. D.R. Mumm, A.G. Evans and I.T. Spitsberg, Characterization of a cyclic displacement instability for a thermally grown oxide in a thermal barrier system, Acta Mater., 2001, 49(12), p 2329-2340.

6. N.M. Yanar, F.S. Pettit and G.H. Meier, Failure characteristics during cyclic oxidation of yttria stabilized zirconia thermal barrier coatings deposited via electron beam physical vapor deposition on platinum aluminide and on NiCoCrAlY bond coats with processing modifications for improved performances, Metall. Mater. Trans. A, 2006, 37(5), p 1563-1580.

7. N. Curry, N. Markocsan, X.-H. Li, A. Tricoire and M. Dorfman, Next generation thermal barrier coatings for the gas turbine industry, J. Therm. Spray Technol., 2011, 20(1-2), p 108-115.

8. T. Strangman, D. Raybould, A. Jameel and W. Baker, Damage mechanisms, life prediction, and development of EB-PVD thermal barrier coatings for turbine airfoils, Surf. Coat. Technol., 2007, 202(4), p 658-664.

9. A. Feuerstein, J. Knapp, T. Taylor, A. Ashary, A. Bolcavage and N. Hitchman, Technical and economical aspects of current thermal barrier coating systems for gas turbine engines by thermal spray and EBPVD: a review, J. Therm. Spray Technol., 2008, 17(2), p 199-213.

10. L. Łatka, A. Cattini, L. Pawlowski, S. Valette, B. Pateyron, J.-P. Lecompte et al., Thermal diffusivity and conductivity of yttria stabilized zirconia coatings obtained by suspension plasma spraying 论, Surf. Coat Technol., 2012, 208, p 87-91.

11. B. Bernard, A. Quet, L. Bianchi, A. Joulia, A. Malié, V. Schick et al., Thermal insulation properties of YSZ coatings: Suspension Plasma Spraying (SPS) versus Electron Beam Physical Vapor Deposition (EB-PVD) and Atmospheric Plasma Spraying (APS), Surf. Coat. Technol., 2017, 318, p 122-128.

12. A. Ganvir, N. Curry, S. Govindarajan and N. Markocsan, Characterization of thermal barrier coatings produced by various thermal spray techniques using solid powder, suspension, and solution precursor feedstock material, Int. J. Appl. Ceram. Technol., 2016, 13(2), p 324-332.

13. S. Rezanka, G. Mauer and R. Vaßen, Improved thermal cycling durability of thermal barrier coatings manufactured by PS-PVD, J. Therm. Spray Technol., 2014, 23(1-2), p 182-189.
14. A. Ganvir, N. Curry, N. Markocsan, P. Nylén and F.-L. Toma, Comparative study of suspension plasma sprayed and suspension high velocity oxy-fuel sprayed YSZ thermal barrier coatings, Surf. Coat. Technol., 2015, 268, p 70-76.

15. H. Tabbara and S. Gu, A study of liquid droplet disintegration for the development of nanostructured coatings, AIChE J., 2012, 58(11), p 3533-3544.

16. H. KaBner and A. Stuke, Stover MRRVD. Influence of porosity on thermal conductivity and sintering in suspension plasma sprayed thermal barrier coatings, Adv. Ceram. Coat. Interfaces III Ceram. Eng. Sci. Proc., 2009, 46, p 147.

17. R.S. Lima, B.M.H. Guerreiro and M. Aghasibeig, Microstructural characterization and room-temperature erosion behavior of Asdeposited SPS, EB-PVD and APS YSZ-based TBCs, J. Therm. Spray Technol., 2019, 28(1-2), p 223-232.

18. G. Mauer, M.O. Jarligo, S. Rezanka, A. Hospach and R. Vaßen, Novel opportunities for thermal spray by PS-PVD, Surf. Coat. Technol., 2015, 268, p 52-57.

19. M. Goral, S. Kotowski and J. Sieniawski, The technology of plasma spray physical vapour deposition, High Temp. Mater. Process., 2013, 32(1), p 33-39.

20. K. von Niessen and M. Gindrat, Plasma spray-PVD: a new thermal spray process to deposit out of the vapor phase, J. Therm. Spray Technol., 2011, 20(4), p 736-743.

21. A. Scrivani, U. Bardi, L. Carrafiello, A. Lavacchi, F. Niccolai and G. Rizzi, A comparative study of high velocity oxygen fuel, vacuum plasma spray, and axial plasma spray for the deposition of CoNiCrAlY bond coat alloy, J. Therm. Spray Technol., 2003, 12(4), p 504-507.

22. N. Curry, K. VanEvery, T. Snyder and N. Markocsan, Thermal conductivity analysis and lifetime testing of suspension plasmasprayed thermal barrier coatings, Coatings, 2014, 4(3), p 630-650.

23. M. Gupta, N. Markocsan, X.-H. Li and R.L. Peng, Improving the lifetime of suspension plasma sprayed thermal barrier coatings, Surf. Coat. Technol., 2017, 332, p 550-559.

24. ImageJ [Internet]. [cited 2020 Aug 10]. Available from: https:// imagej.nih.gov/ij/

25. A. Ganvir, N. Curry, S. Björklund, N. Markocsan and P. Nylén, Characterization of microstructure and thermal properties of YSZ coatings obtained by axial suspension plasma spraying (ASPS), $J$. Therm. Spray Technol., 2015, 24(7), p 1195-1204.

26. A.G. Evans and E.A. Charles, Fracture toughness determinations by indentation, J. Am. Ceram. Soc., 1976, 59(7-8), p 371-372.

27. R.E. Taylor, Thermal conductivity determinations of thermal barrier coatings, Mater. Sci. Eng. A., 1998, 245(2), p 160-167.

28. N. Curry and J. Donoghue, Evolution of thermal conductivity of dysprosia stabilised thermal barrier coating systems during heat treatment, Surf. Coat. Technol., 2012, 209, p 38-43.

29. S. Mahade, N. Curry, S. Björklund, N. Markocsan and P. Nylén, Thermal conductivity and thermal cyclic fatigue of multilayered $\mathrm{Gd}_{2} \mathrm{Zr}_{2} \mathrm{O}_{7} / \mathrm{YSZ}$ thermal barrier coatings processed by suspension plasma spray, Surf Coat Technol., 2015, 283, p 329-336.

30. M. Gupta, N. Markocsan, X.-H. Li and L. Östergren, Influence of Bondcoat spray process on lifetime of suspension plasma-sprayed thermal barrier coatings, J. Therm. Spray Technol., 2018, 27(1), p 84-97.

31. B. Siebert, C. Funke, R. Vaßen and D. Stöver, Changes in porosity and Young's Modulus due to sintering of plasma sprayed thermal barrier coatings, J. Mater. Process. Technol., 1999, 92-93, p 217-223.

32. W. He, G. Mauer, A. Schwedt, O. Guillon and R. Vaßen, Advanced crystallographic study of the columnar growth of YZS coatings produced by PS-PVD, J. Eur. Ceram. Soc., 2018, 38(5), p 2449-2453. 
33. A. Ganvir, S. Joshi, N. Markocsan and R. Vassen, Tailoring columnar microstructure of axial suspension plasma sprayed TBCs for superior thermal shock performance, Mater. Des., 2018, 144, p 192-208.

34. F. Cernuschi, P. Bison and A. Moscatelli, Microstructural characterization of porous thermal barrier coatings by laser flash technique, Acta Mater., 2009, 57(12), p 3460-3471.

35. R. Vaßen, E. Bakan, D. Mack, S. Schwartz-Lückge, D. Sebold, Y. Jung Sohn et al., Performance of YSZ and $\mathrm{Gd}_{2} \mathrm{Zr}_{2} \mathrm{O}_{7} / \mathrm{YSZ}$ double layer thermal barrier coatings in burner rig tests, J. Eur. Ceram. Soc., 2020, 40(2), p 480-490.

36. G. Dwivedi, V. Viswanathan, S. Sampath, A. Shyam and E. LaraCurzio, Fracture toughness of plasma-sprayed thermal barrier ceramics: influence of processing, microstructure, and thermal aging, J. Am. Ceram. Soc., 2014, 97(9), p 2736-2744.

37. D. Zhou, O. Guillon and R. Vaßen, Development of YSZ thermal barrier coatings using axial suspension plasma spraying, Coatings, 2017, 7(8), p 120.

38. J.R. Nicholls, K.J. Lawson, A. Johnstone and D.S. Rickerby, Methods to reduce the thermal conductivity of EB-PVD TBCs, Surf Coat Technol., 2002, 151-152, p 383-391.

39. I.O. Golosnoy, S.A. Tsipas and T.W. Clyne, An analytical model for simulation of heat flow in plasma-sprayed thermal barrier coatings, J. Therm. Spray Technol., 2005, 14(2), p 205-214.

40. Effect of manufacturing related parameters on oxidation properties of MCrAlY-bondcoats - Subanovic - 2008 - Materials and Corrosion - Wiley Online Library [Internet]. [cited 2020 Dec 23]. Available from: https://onlinelibrary.wiley.com/doi/full/10.1002/ maco.200804128?casa_token=sH6kT5sqVk8AAAAA\%3AtLiyR IC9jAK-AeaiRu6JaktudxR9zE9byj_xFu6DN05o q4AYvmkSueog_sPyb7_4owCSyif_yrMhE2A

41. E. Hejrani, D. Sebold, W.J. Nowak, G. Mauer, D. Naumenko, R. Vaßen et al., Isothermal and cyclic oxidation behavior of free standing MCrAlY coatings manufactured by high-velocity atmospheric plasma spraying, Surf. Coat. Technol., 2017, 313, p 191-201.

42. B. Bernard, A. Quet, L. Bianchi, V. Schick, A. Joulia, A. Malié et al., Effect of suspension plasma-sprayed YSZ columnar microstructure and bond coat surface preparation on thermal barrier coating properties, J. Therm. Spray Technol., 2017, 26(6), p 1025-1037.

43. M. Ahrens, R. Vaßen, D. Stöver and S. Lampenscherf, Sintering and creep processes in plasma-sprayed thermal barrier coatings, J. Therm. Spray Technol., 2004, 13(3), p 432-442.

44. O. Aranke, M. Gupta, N. Markocsan, X.-H. Li and B. Kjellman, Microstructural evolution and sintering of suspension plasmasprayed columnar thermal barrier coatings, J. Therm. Spray Technol., 2019, 28(1-2), p 198-211.

45. B. Xiao, X. Huang, T. Robertson, Z. Tang and R. Kearsey, Sintering resistance of suspension plasma sprayed 7YSZ TBC under isothermal and cyclic oxidation, J. Eur. Ceram. Soc., 2020, 40(5), p 2030-2041.

46. C. Nordhorn, R. Mücke, D.E. Mack and R. Vaßen, Probabilistic lifetime model for atmospherically plasma sprayed thermal barrier coating systems, Mech. Mater., 2016, 93, p 199-208.

47. D. Zhou, D.E. Mack, P. Gerald, O. Guillon and R. Vaßen, Architecture designs for extending thermal cycling lifetime of suspension plasma sprayed thermal barrier coatings, Ceram. Int., 2019, 45(15), p 18471-18479.

48. M. Gupta, X.-H. Li, N. Markocsan and B. Kjellman, Design of high lifetime suspension plasma sprayed thermal barrier coatings, J. Eur. Ceram. Soc., 2020, 40(3), p 768-779.

Publisher's Note Springer Nature remains neutral with regard to jurisdictional claims in published maps and institutional affiliations. 